\title{
Aspectos quantitativos e qualitativos do grão de trigo influenciados por nitrogênio e lâminas de água
}

\author{
Ana P. M. Boschini ${ }^{1}$, Cícero L. da Silva ${ }^{1}$, C arlos A. da S. 0 liveira ${ }^{1}$, \\ Manuel P. de O liveira Júnior ${ }^{1}$, Martha Z. de Miranda ${ }^{2} \&$ Marcelo Fagioli $^{1}$
}

RESU MO

Com o objetivo de avaliar o efeito de diferentes lâminas de água e doses de nitrogênio e a interação dos dois fatores sobre a produtividade e qualidade de grãos do trigo BRS 254 instalou-se, em 2009, um experimento em Latossolo Vermelho-Amarelo. 0 delineamento experimental foi o de blocos ao acaso com parcelas subdivididas e quatro repetições. $\mathrm{N}$ as parcelas foram estabelecidas cinco doses de nitrogênio (N): 20, 50, 100, 200 e $400 \mathrm{~kg} \mathrm{ha}^{-1}$ e nas subparcelas as lâminas de água: 120; 264; 342 e $392 \mathrm{~mm}$. A produtividade média e a maioria de seus componentes diferiram significativamente em função da lâmina de água e da dose de $\mathrm{N}$; a exceção foi o número de espiguetas por espiga, não influenciado por nitrogênio. A produtividade mínima e máxima observada foi de 1.136 e $5.209 \mathrm{~kg} \mathrm{ha}^{-1}$, respectivamente, para $120 \mathrm{~mm}$ e $50 \mathrm{~kg} \mathrm{ha}^{-1}$ de N e $392 \mathrm{~mm}$ e $200 \mathrm{~kg} \mathrm{ha}^{-1}$ de N. O teor de proteína bruta foi influenciado significativamente pela interação lâmina de água e dose de nitrogênio. A massa do hectolitro, a energia de deformação da massa e o número de queda, foram influenciados significativamente apenas por lâmina de água. Lâminas menores que $365 \mathrm{~mm}$ proporcionaram massa do hectolitro abaixo de $78 \mathrm{~kg} \mathrm{hL}^{-1}$. Por outro lado, lâminas de água maiores que $340 \mathrm{~mm}$ proporcionaram número de queda abaixo de $250 \mathrm{~s}$, sugerindo cautela no manejo da água em agrossistemas de trigo.

Palavras-chave: Triticum aestivum, adubação nitrogenada, irrigação

\section{Q uantitative and qualitative aspects of wheat grains influenced by nitrogen and water depth}

\begin{abstract}
A field experiment was carried out in a Red-Yellow Latosol in 2009 in order to assess the effects of different doses of nitrogen fertilization and water depth and their interaction on the grain yield and quality of wheat BRS 254. The experimental design was a completely randomized block with split plot on water level and four replications. Nitrogen doses in the plot were: 20,50, 100, 200, and $400 \mathrm{~kg} \mathrm{ha}^{-1}$. In the split plot water depths were: 120, 264, 342 and $392 \mathrm{~mm}$. Mean yield and the majority of its components differed significantly with water depth and nitrogen dose. The exception occurred on the number of grains per spikelet which was not affected by nitrogen level. M inimum and maximum yield were 1,135 $\mathrm{kg} \mathrm{ha}^{-1}$ and $5,209 \mathrm{~kg} \mathrm{ha}^{-1}$, respectively for $120 \mathrm{~mm}$ and $50 \mathrm{~kg} \mathrm{ha}^{-1}$ of $\mathrm{N}$; and $392 \mathrm{~mm}$ and $200 \mathrm{~kg} \mathrm{ha}^{-1}$ of $\mathrm{N}$. In all of them, the highest yields were achieved by nitrogen doses over $220 \mathrm{~kg} \mathrm{ha}^{-1}$. Crude protein content was significantly affected by water and nitrogen level interaction. The hectoliter mass, the strength of gluten and the falling number were significantly affected by water level. W ater depths lower than 365 $\mathrm{mm}$ provided hectoliter weight below $78 \mathrm{~kg} \mathrm{hL}^{-1}$. O n the other hand water depths higher than $340 \mathrm{~mm}$ provided falling number below $250 \mathrm{~s}$, suggesting caution on wheat agrossystems water management.
\end{abstract}

Key words: Triticum aestivum, nitrogen fertilization, irrigation

\footnotetext{
${ }^{1}$ UnB, Campus U niversitário D arcy Ribeiro, CEP 70910-900, Brasília, DF. Fone (61) 3307-2430. E-mail: anaboschini@yahoo.com.br; cicero@unb.br; dasilvao@unb.br; manueljr@unb.br; mfagioli@unb.br

Embrapa Trigo, Rodovia BR 285, km 294, CEP 990001-970, Passo Fundo, RS. Fone: (54) 3316- 5800. E-mail: marthaz@cnpt.embrapa.br
} 


\section{INTRODUÇÃO}

No Cerrado brasileiro a área cultivada com trigo aumentou consideravelmente nos últimos anos devido ao desenvolvimento de cultivares adaptadas às condições edafoclimáticas da região (Trindade et al., 2006). Temperaturas médias inferiores a $25^{\circ} \mathrm{C}$ e temperaturas baixas durante a noite, favorecem o crescimento e o desenvolvimento deste cultivo na região. A cultivar BRS 254 é uma das mais promissoras para o plantio irrigado na região. Dentre os fatores que motivam a utilização desta cultivar pelo produtor estão a adaptabilidade local, a qualidade do grão e a resistência, mesmo que moderada, ao acamamento e à germinação natural na espiga e, principalmente, seu alto potencial em rendimento de grãos (EMBRAPA, 2008).

O rendimento de grãos é o produto final de uma série de interações que ocorrem no agrossistema de trigo. As interações envolvem o potencial genético da semente e inúmeros outros fatores, tais como: a disponibilidade de calor e radiação; água e nutrientes; a ocorrência de pragas, doenças e plantas daninhas que afetam o crescimento e o desenvolvimento da planta e, consequentemente, o produto final de interesse socioeconômico, os grãos (EMBRAPA, 2004), ante o que se pode afirmar que o potencial genético de uma cultivar será expresso somente quando existirem condições edafoclimáticas e de manejo do agrossistema adequadas.

Na região do Cerrado o bom desempenho da lavoura de trigo vem sendo garantido pela adoção de modernas técnicas de cultivo, dentre as quais se destacam, segundo Mistro \& Camargo (2002): o emprego da irrigação por aspersão; colheita mecanizada e genótipos de trigo de baixo porte, resistentes ao acamamento, vegetação com palha forte e responsiva às adubações, sobremaneira à adubação nitrogenada. Neste contexto, a irrigação e a adubação nitrogenada merecem destaque não apenas pelo custo que representam mas, sobretudo, em razão da necessidade de se utilizar esses recursos de modo eficiente garantindo, assim, a sustentabilidade do agrossistema na região.

A otimização do uso dos fatores envolvidos na produção agropecuária é possibilitada pelo uso de funções de produção. Para o fator água, o estabelecimento dessa função tem sido proporcionado utilizando-se da irrigação por aspersão em linha (line source sprinkler system). Hanks et al. (1976), afirmaram que esta metodologia possibilita coletar dados e estabelecer estimativas da variável dependente da produção, a partir de inúmeras variáveis independentes, como nível de água, fertilizante e outras.

No Brasil, estudos sobre a resposta de genótipos de trigo a doses de água e adubação nitrogenada, foram relatados por Frizzone et al. (1996), Scalco et al. (2002), Trindade et al. (2006), entre outros. Em Sete Lagoas, MG, Frizzone et al. (1996) verificaram máxima produtividade da cultivar BR 10-Formosa com $274 \mathrm{~mm}$ de água e $80 \mathrm{~kg} \mathrm{ha}^{-1}$ de $\mathrm{N}$ e constataram que o número de grãos por espiga aumentou com a aplicação de nitrogênio e água, atingindo o máximo de 40,7 com $157 \mathrm{~mm}$ de água e $160 \mathrm{~kg} \mathrm{ha}^{-1} \mathrm{de} \mathrm{N}$.

Segundo Guarienti et al. (2003), a qualidade do grão de trigo pode ser definida mediante testes físico-químicos (massa do hectolitro, massa de mil grãos, número de queda) e reológicos (alveografia, farinografia). As características definidas por esses testes assumem significados diferentes que dependem da designação de uso do produto; a aplicação de água e nitrogênio na lavoura de trigo também afeta a qualidade do grão.

Conceitos relativos envolvendo a qualidade do grão de trigo dependem do segmento que avalia (Schroeder, 1987). Para o moageiro a qualidade significa matéria-prima uniforme em tamanho e forma; alto peso específico; alto rendimento em farinha e baixos teores de cinza, dentre outros aspectos. Para o panificador, a farinha de qualidade deve possuir alta capacidade de absorção de água, boa tolerância à mistura, glúten balanceado e alta porcentagem de proteínas. Para o consumidor, o trigo de qualidade é aquele capaz de produzir pães de grande volume, com texturas interna e externa adequadas, cor clara e alto valor nutritivo.

Assim, percebe-se a necessidade de pesquisas que visem à correta utilização de água e nitrogênio em agrossistemas de trigo. O objetivo deste trabalho é avaliar o efeito de diferentes lâminas de água e doses de nitrogênio e a interação desses dois fatores sobre a produtividade e a qualidade de grãos do trigo BRS 254.

\section{Material e MÉTOdos}

O experimento foi conduzido no período de maio a setembro de 2009, na Fazenda Água Limpa, da Universidade de Brasília, em uma área de coordenadas geográficas aproximadamente iguais a $15^{\circ} 56^{\prime} \mathrm{S}$ e $47^{\circ} 56^{\prime} \mathrm{W}$ e altitude de $1080 \mathrm{~m}$. O solo da área experimental é classificado como Latossolo Vermelho-Amarelo distrófico (LVAd), de textura franco-argilo-arenosa. Os resultados da análise química do solo, obtidos antes do início do experimento, estão apresentados na Tabela 1.

Utilizou-se a cultivar de trigo BRS 254, recomendada para cultivo sob irrigação, de ciclo médio, porte médio e moderadamente resistente ao acamamento e à debulha natural (EMBRAPA, 2008). Após calagem e preparo adequado do solo, em 20/05/2009, realizou-se a semeadura mecanizada de 15 linhas por subparcela, no espaçamento de $0,20 \mathrm{~cm}$, profundidade de 5 $\mathrm{cm}$ e densidade de 320 sementes por $\mathrm{m}^{2}$.

Com base na análise química do solo realizou-se a adubação de plantio, que consistiu de 20,120, $20 \mathrm{e} 1 \mathrm{~kg} \mathrm{ha}^{-1}$ de nitrogênio

Tabela 1. Resultados da análise química do solo da área experimental, classificado como Latossolo Vemelho-Amarelo distrófico (LVAd)

\begin{tabular}{|c|c|c|c|c|c|c|c|c|c|c|c|}
\hline \multirow{2}{*}{ Camada } & \multirow{2}{*}{$\mathrm{pH}$} & \multirow{2}{*}{$P(p p m)$} & $\mathrm{Ca}$ & $\mathrm{Mg}$ & K & $\mathrm{Na}$ & Al & $\mathrm{H}+\mathrm{Al}$ & CTC & \multirow{2}{*}{ V (\%) } & \multirow{2}{*}{ M.O. } \\
\hline & & & \multicolumn{7}{|c|}{$\left(\mathrm{cmol}_{\mathrm{c}} \mathrm{cm}^{-3}\right)$} & & \\
\hline $0-20$ & 6,1 & 1,8 & 2,2 & 0,3 & 0,19 & 0,01 & 0 & 3,7 & 6,4 & 42,19 & 48,85 \\
\hline
\end{tabular}

Donde: $\mathrm{pH}=$ potencial hidrogeniônico; $\mathrm{P}=$ fósforo; $\mathrm{Ca}=$ Cálcio; $\mathrm{Mg}=$ magnésio; $\mathrm{K}=$ potássio; $\mathrm{Na}=$ sódio; $\mathrm{Al}=$ alumínio; $\mathrm{H}+\mathrm{Al}=$ acidez potencial; $\mathrm{CTC}=$ capacidade de troca catiônica; $\mathrm{V}=$ saturação por bases; M.O. = matéria orgânica 
$(\mathrm{N})$, fósforo $\left(\mathrm{P}_{2} \mathrm{O}_{5}\right)$, potássio $\left(\mathrm{K}_{2} \mathrm{O}\right)$ e boro $(\mathrm{B})$, respectivamente. Utilizaram-se, como fertilizantes, o sulfato de amônio, o superfosfato simples, o cloreto de potássio e o bórax. O suplemento de boro foi fornecido para evitar a perda de viabilidade dos grãos de pólen.

A adubação nitrogenada foi realizada em cobertura aplicando-se sulfato de amônio nas linhas de plantio, no início do estádio de perfilhamento cuja ocorrência se deu 15 dias após a emergência do trigo. As doses de sulfato de amônio aplicadas foram de $0,150,400,900$ e $1900 \mathrm{~kg} \mathrm{ha}^{-1}$, correspondentes a $0,30,80,180$ e $380 \mathrm{~kg} \mathrm{ha}^{-1} \mathrm{de} \mathrm{N}$.

Para evitar o acamamento das plantas foram aplicados $125 \mathrm{~g}$ $\mathrm{ha}^{-1}$ de trinexapac-ethyl, correspondentes a $500 \mathrm{~mL} \mathrm{ha}^{-1} \mathrm{de}$ Moddus; na época da aplicação as plantas de trigo apresentavam de 3 a 4 perfilhos, com os $1^{\circ}$ e $2^{\circ}$ nós visíveis, estatura entre 30 e $35 \mathrm{~cm}$ e desenvolvimento normal.

Lâminas leves de irrigação no total de $32 \mathrm{~mm}$ de água, foram aplicadas em todo o experimento, até a emergência plena das plantas. A partir de então, utilizando-se o método de aspersão em linha, os tratamentos de irrigação foram obtidos em função do gradiente decrescente de água, proporcionado por emissores instalados na linha e espaçados 6 m entre si (Hanks et al., 1976). Foram usados emissores com bocais de 4,0 e 5,0 mm trabalhando com pressão de serviço de $300 \mathrm{kPa}$.

As distâncias da linha de aspersores ao centro de cada subparcela foram: 2,$5 ; 5,9 ; 9,3$ e $12,7 \mathrm{~m}$, de forma a proporcionar as lâminas de irrigação $\mathrm{L}_{4}, \mathrm{~L}_{3}, \mathrm{~L}_{2} \mathrm{e} \mathrm{L}_{1}$, respectivamente. A aplicação das lâminas de irrigação foi controlada por três linhas de coletores e, em cada subparcela, foram utilizados dois coletores. As irrigações foram realizadas quando a tensão do solo, controlada por tensiômetros instalados nas parcelas $\mathrm{L}_{3} \mathrm{a}$ $10 \mathrm{~cm}$ de profundidade, atingia $40 \mathrm{kPa}$. Com a tensão supracitada e o teor de água correspondente à capacidade de campo, obteve-se uma diferença no teor de água de $0,06 \mathrm{~cm}^{3} \mathrm{~cm}^{-3}$; multiplicando-se este valor por uma profundidade de solo de $200 \mathrm{~mm}$, obteve-se uma lâmina de irrigação de $12 \mathrm{~mm}$, a qual foi usada no restante do ciclo da cultura, permitindo a diferenciação das lâminas supracitadas.

O delineamento experimental usado foi blocos casualizados, com parcelas subdivididas e quatro repetições. Nas parcelas foram aleatorizadas as cinco doses de nitrogênio em cobertura e nas subparcelas foram aplicadas as quatro lâminas de irrigação, de forma não casualizada, em razão da metodologia utilizada. Cada subparcela apresentou dimensões de 3 x $6 \mathrm{~m}$ $\left(18 \mathrm{~m}^{2}\right)$. Desta área se colheu apenas a área útil de 1,8 x $5 \mathrm{~m}$ (9 $\mathrm{m}^{2}$ ), correspondente às linhas de plantas centrais da subparcela.

A colheita do trigo foi realizada manual e individualmente por unidade experimental, aos 111 dias após a emergência plena das plantas, quando cerca de $90 \%$ das espigas apresentavam grãos com coloração típica de maduro e teor de água médio de $12 \%$; posteriormente, parte do material colhido foi submetido a trilhagem mecânica.

Dez espigas de trigo foram colhidas ao acaso na área útil de cada subparcela; em seguida, foram acondicionadas em sacos de papel, devidamente identificadas e levadas ao laboratório para as seguintes determinações: número de espiguetas por espiga, número de grãos por espiga e número de grãos por espigueta. O número de espiguetas por espiga e o número de grãos por espiga, foram obtidos por meio do número médio de espiguetas e do número médio de grãos das dez espigas, respectivamente. Obteve-se o número de grãos por espigueta através da divisão do número de grãos por espiga pelo número de espiguetas por espiga, de cada unidade experimental.

A produtividade e o número de grãos por $\mathrm{m}^{2}$ foram determinados a partir da colheita das plantas contidas em $2 \mathrm{e}$ $0,5 \mathrm{~m}^{2}$ da área útil de cada subparcela, respectivamente. $\mathrm{Na}$ determinação da produtividade os grãos foram trilhados e pesados obtendo-se a seguir, a produtividade em $\mathrm{kg} \mathrm{ha}^{-1}$ a $13 \%$ de umidade (base úmida); para a determinação do número de grãos por $\mathrm{m}^{2}$, os grãos foram trilhados, contados e os dados transformados em número de grãos por $\mathrm{m}^{2}$.

Determinou-se o teor de proteína bruta nos grãos utilizandose uma amostra de 50g de grãos da área útil; os grãos, por sua vez, foram moídos em moinhos do tipo centrífuga, modelo TE631 e, para a determinação do nitrogênio total, empregou-se o método de Kjeldahl, utilizando-se o fator de conversão de 6,25 para o cálculo da proteína bruta presente no grão.

A massa do hectolitro, em $\mathrm{kg} \mathrm{hL}^{-1}$, foi determinada segundo método descrito por Brasil (1992), em balança Dalle Molle. A determinação da massa de mil grãos foi realizada conforme método descrito por Brasil (1992), em que se realiza a contagem manual de 100 grãos de trigo de cada subparcela que, a seguir, são pesados em balança semianalítica. O resultado é multiplicado por 10 para que seja expresso em mil grãos.

O número de queda da farinha de trigo, em segundos, foi determinado no laboratório de qualidade de grãos da Embrapa Trigo, na cidade de Passo Fundo, RS, cujos resultados foram corrigidos para altitude local. A análise foi realizada em equipamento Falling Number, modelo FN 1900, de acordo com o Método 56-81B da American Association of Cereal Chemists (AACC, 2000) e o Manual de Operação do equipamento. Determinou-se a energia de deformação da massa no alveógrafo Chopin, modelo NG (Villeneuve-la-Garenne Cedex, França) utilizando-se o método ${ }^{\circ}$ 54-30A, da American Association of Cereal Chemists (AACC, 2000).

A análise estatística foi feita com o aplicativo MSTATC da Universidade de Michigan. Os dados foram submetidos à análise de variância preliminar para detectar as prováveis interações. Os dados de produtividade de grãos foram submetidos à análise de regressão de múltiplas variáveis, sendo a resposta da produtividade à aplicação de água e nitrogênio representada pelo modelo $\mathrm{Y}=\mathrm{b}_{0}+\mathrm{b}_{1} \mathrm{~L}+\mathrm{b}_{2} \mathrm{~N}+\mathrm{b}_{11} \mathrm{~L}^{2}+\mathrm{b}_{22} \mathrm{~N}^{2}+$ $\mathrm{b}_{12} \mathrm{LN}+\hat{\mathrm{i}}$, em que Y é a produtividade de grãos $\left(\mathrm{kg} \mathrm{ha}^{-1}\right), \mathrm{b}_{0}, \mathrm{~b}_{1}$, $\mathrm{b}_{2}, \mathrm{~b}_{11}, \mathrm{~b}_{22}$ e $\mathrm{b}_{12}$ são os coeficientes de regressão, Lé a lâmina de água em mm, $\mathrm{N}$ é a dose de nitrogênio em $\mathrm{kg} \mathrm{ha}^{-1}$ e î é o erro estatístico da regressão (Oliveira Júnior et al., 2010).

As médias do número de grãos por espiga, do número de grãos por espigueta, do número de grãos por $\mathrm{m}^{2} \mathrm{e}$ da massa de mil grãos, foram analisadas por regressão simples para o efeito de nitrogênio. Foram ajustadas funções de resposta para as variáveis dependentes, número de espiguetas por espiga, massa do hectolitro, energia de deformação da massa e número de queda, em função da variável dependente lâmina de água, por meio da análise de regressão simples, selecionando-se o modelo de maior coeficiente de determinação e de melhor 
representatividade da relação de causa e efeito esperada para cada variável dependente.

\section{RESULTADOS E DisCUSSÃO}

Conforme dados obtidos na Estação Agroclimática da Fazenda Água Limpa no período do experimento, ocorreu precipitação total de $36 \mathrm{~mm}$. Observaram-se as temperaturas máxima de $30,9^{\circ} \mathrm{C}$, a mínima de $6,3^{\circ} \mathrm{C}$ e a média de $19,2^{\circ} \mathrm{C}$. A umidade relativa média do ar correspondeu a $72,6 \%$. As lâminas de água decorrentes das irrigações aplicadas, incluindo a lâmina inicial de uniformização e as precipitações verificadas no período de realização do experimento, totalizaram 120, 264, 342 e $392 \mathrm{~mm}$, respectivamente para $\mathrm{L}_{4}, \mathrm{~L}_{3}, \mathrm{~L}_{2} \mathrm{e} \mathrm{L}_{1}$.

Neste experimento observou-se produtividade mínima de $1.136 \mathrm{~kg} \mathrm{ha}^{-1} \mathrm{e}$ máxima de $5.209 \mathrm{~kg} \mathrm{ha}^{-1}$, respectivamente para a lâmina de água de $120 \mathrm{~mm}$ e dose de $\mathrm{N}$ de $50 \mathrm{~kg} \mathrm{ha}^{-1}$ e lâmina de água de $392 \mathrm{~mm}$ e dose de $\mathrm{N}$ de $200 \mathrm{~kg} \mathrm{ha}^{-1}$ (Tabela 2).

Tabela 2. Produtividade média observada, em kg ha-1, em função da lâmina de água (L), em $\mathrm{mm}$, e da dose de nitrogênio ( $\mathrm{N}$ ), em kg ha-1 (semeadura + cobertura)

\begin{tabular}{cccccc}
\hline \multirow{2}{*}{$\mathbf{(}(\mathbf{m m})$} & \multicolumn{5}{c}{ Dose de N, em kg ha } \\
\cline { 2 - 6 } & $\mathbf{2 0}$ & $\mathbf{5 0}$ & $\mathbf{1 0 0}$ & $\mathbf{2 0 0}$ & $\mathbf{4 0 0}$ \\
120 & 1137 & 1136 & 1319 & 1352 & 1423 \\
264 & 2818 & 3076 & 3404 & 3890 & 3499 \\
342 & 2706 & 3457 & 3823 & 4848 & 4537 \\
392 & 3652 & 4066 & 4847 & 5209 & 5201 \\
\hline
\end{tabular}

A análise de variância mostrou efeito significativo da lâmina de água e da dose de nitrogênio sobre a produtividade, número de grãos por espiga, número de grãos por espigueta, número de grãos por $\mathrm{m}^{2}$ e massa de mil grãos (Tabela 3 ). $\mathrm{O}$ número de espiguetas por espiga, a massa do hectolitro, a energia de deformação da massa e o número de queda, foram influenciados significativamente apenas pela lâmina de água; para o teor de proteína bruta notou-se influência significativa da lâmina de água, da dose de nitrogênio e da interação desses fatores. Apesar de o efeito da lâmina de água ser um tanto previsível e

Tabela 3. Resumo da análise de variância para produtividade de grãos de trigo (PROD), número de grãos por espiga (NGE), número de espiguetas por espiga ( $\mathrm{NeE}$ ), número de grãos por espigueta ( $\mathrm{N} \mathrm{Ge}$ ), número de grãos por $\mathrm{m}^{2}(\mathrm{NG})$, massa de mil grãos (MMG), massa do hectolitro ( $\mathrm{MH}$ ), energia de deformação da massa (W), número de queda (N Q ) e teor de proteína bruta (PB) sob cinco doses de nitrogênio ( $\mathrm{N}$ ), quatro lâminas de água (L) e quatro blocos

\begin{tabular}{ccccccccccc}
\hline $\begin{array}{c}\text { Fonte de } \\
\text { variação }\end{array}$ & PROD & NGE & NeE & NGe & NG & MMG & MH & W & NQ & PB \\
Bloco & $* *$ & NS & NS & NS & $* *$ & NS & NS & NS & NS & NS \\
N & $* *$ & $* *$ & NS & $* *$ & $* *$ & $*$ & NS & NS & NS & $* *$ \\
$\mathrm{~L}^{1}$ & $* *$ & $* *$ & $* *$ & $* *$ & $* *$ & $* *$ & $* *$ & $* *$ & $* *$ & $* *$ \\
N x L & NS & NS & NS & NS & NS & NS & NS & NS & NS & $* *$ \\
\hline
\end{tabular}

Análise não válida para a fonte de variação em questão

$\mathrm{NS}=$ não significativo; ${ }^{*}$ significativo a 0,05 de probabilidade pelo teste $\mathrm{F} ;{ }^{*} *$ significativo 0,01 de probabilidade pelo teste $\mathrm{F}$ altamente significativo em todas as variáveis dependentes estudadas, vale ressaltar sua não validade estatística, pela não casualização deste fator.

Utilizando a análise de regressão múltipla para verificar a influência da dose de nitrogênio e da lâmina de água na produtividade de grãos, verificou-se haver elevada probabilidade de que as diferenças de produtividade sejam explicadas por essas duas variáveis independentes (Tabela 4). Realizou-se a análise de regressão múltipla apenas para a produtividade, por ela resumir o comportamento das demais variáveis (número de grãos por espiga, número de grãos por espigueta, número de grãos por $\mathrm{m}^{2} \mathrm{e}$ massa de mil grãos) e por ela ser a variável mais importante do ponto de vista do produtor. Em função do maior coeficiente $(9,973)$ observado na variável água, depreende-se que esta exerce um efeito maior na produtividade e seus componentes do que a variável nitrogênio.

Tabela 4. Análise de variância da regressão múltipla para a variável dependente produtividade, em função das variáveis: doses de nitrogênio e lâminas de água

\begin{tabular}{lrrrc}
\hline $\begin{array}{c}\text { Fonte de } \\
\text { variação }\end{array}$ & GL & \multicolumn{1}{c}{ SQM } & F & Probabilidade \\
Regressão & 4 & 8744930,35 & 106,06 & $0,000 * *$ \\
Resíduo & 15 & 81914,94 & & \\
Total & 19 & & & \\
** significativo a 1\% de probabilidade pelo teste F & &
\end{tabular}

Pela análise de regressão e se considerando as variáveis independentes com significância maior ou igual a 95\%, foi possível estabelecer a Eq. 1 com coeficiente de determinação $R^{2}$ igual a 0,97 . Esta equação permite estimar a produtividade em função da lâmina de água e dose de nitrogênio, nas condições experimentais usadas e dentro dos intervalos avaliados.

$$
\begin{gathered}
\mathrm{Y}=-399,176+9,973 \mathrm{~L}+7,853 \mathrm{~N}-2,059 \times 10^{-2} \mathrm{~N}^{2}+ \\
+1,275 \times 10^{-2} \mathrm{LN}
\end{gathered}
$$

em que:
$\mathrm{Y}$ - produtividade, $\mathrm{kg} \mathrm{ha}^{-1}$
$\mathrm{N}$ - dose de nitrogênio, $\mathrm{kg} \mathrm{ha}^{-1}$
L - lâmina de água, mm

Apesar da análise de variância não mostrar efeito significativo da interação, a equação de regressão leva em conta este efeito (LN) entre lâmina de água e dose de nitrogênio, por apresentar coeficiente significativo neste termo; além do mais, a equação com esta interação melhora as estimativas da produtividade.

Por ser o coeficiente relativo a $\mathrm{N}^{2}$ na Eq. 1 menor que zero infere-se que, para cada lâmina de água, existe uma dose ótima de nitrogênio (Tabela 5). É oportuno explicar que as equações apresentadas na Tabela 5 foram obtidas por meio da substituição das lâminas de água na Eq. 1; desta forma, as referidas equações possuem o mesmo coeficiente de determinação da Eq. 1 .

Considerando o efeito do nitrogênio em cada lâmina de água (Figura 1), pode-se constatar que a produtividade apresentou resposta quadrática ao aumento da dose de nitrogênio para 
Tabela 5. Equações de regressão da produtividade ( $\mathrm{Y}$ ) em função da dose de nitrogênio (N) nas diferentes lâminas de água, doses de $\mathrm{N}$ otimizadas para cada lâmina de água e produtividade máxima otimizada pelas respectivas equações para cada lâmina de água e dose de $\mathrm{N}$ otimizada

\begin{tabular}{|c|c|c|c|}
\hline $\begin{array}{l}\text { Lâmina de água } \\
\text { (mm) }\end{array}$ & Equação de regressão & $\begin{array}{l}\text { Dose de N otimizada } \\
\left(\mathrm{kg} \mathrm{ha}^{-1}\right)\end{array}$ & $\begin{array}{l}\text { Produtividade otimizada } \\
\left(\mathrm{kg} \mathrm{ha}^{-1}\right)\end{array}$ \\
\hline $\begin{array}{l}120 \\
264 \\
342 \\
392\end{array}$ & $\begin{array}{l}Y=-0,0206 N^{2}+9,383 N+797,58 \\
Y=-0,0206 N^{2}+11,219 N+2233,7 \\
Y=-0,0206 N^{2}+12,214 N+3011,6 \\
Y=-0,0206 N^{2}+12,851 N+3510,2\end{array}$ & $\begin{array}{l}228 \\
272 \\
297 \\
312\end{array}$ & $\begin{array}{l}1867 \\
3762 \\
4823 \\
5515\end{array}$ \\
\hline
\end{tabular}

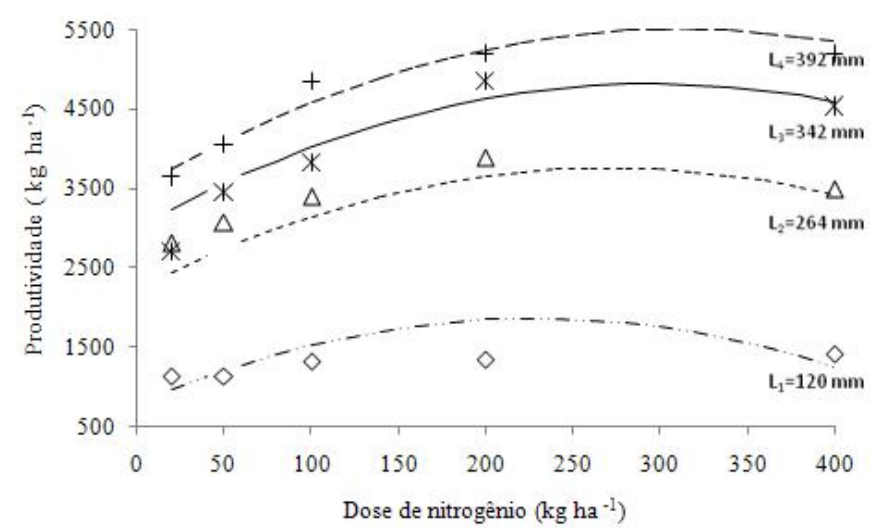

Figura 1. Produtividade observada (pontos) e simulada do trigo (linhas) em kg ha-1 em função de cinco doses de nitrogênio e quatro lâminas de água

todas as lâminas de água aplicadas. Obviamente, as estimativas de produtividade levam em conta a interação entre lâmina de água e dose de nitrogênio do modelo ajustado.

Na Figura 1 os maiores desvios entre as produtividades observadas e simuladas foram verificados nas menores produtividades. Observaram-se produtividades inferiores a $1867 \mathrm{~kg} \mathrm{ha}^{-1}$ para os tratamentos correspondentes a $120 \mathrm{~mm}$ de lâmina de água. A razão de se ter obtido menores produtividades na condição de menor disponibilidade hídrica, pode advir do fato de a absorção de nitrogênio ocorrer principalmente por fluxo de massa, processo este retardado na condição de déficit hídrico no solo; alem do mais, déficit hídricos rigorosos impedem o adequado processo fotossintético da planta. Foram observadas produtividades crescentes quando se aumentou a lâmina de água aplicada.

As médias de produtividade da região Centro-Oeste e do Brasil na safra de 2008/2009, foram iguais a 2.449 e $2.482 \mathrm{~kg} \mathrm{ha}^{-1}$ segundo a Companhia Nacional de Abastecimento (CONAB, 2009), respectivamente, superiores apenas às das produtividades observadas na lâmina de água de $120 \mathrm{~mm}$ em qualquer dose de nitrogênio. Por outro lado, a média de produtividade no Distrito Federal foi, nessa mesma safra, de $5.246 \mathrm{~kg} \mathrm{ha}^{-1}$ (CONAB, 2009).

As produtividades de trigo máximas ajustadas obtidas nas lâminas de água de 120, 264, 342 e 392 mm, com as doses otimizadas de nitrogênio, foram 1867, 3762, 4823 e $5515 \mathrm{~kg} \mathrm{ha}^{-1}$, respectivamente (Tabela 5).

Vários trabalhos também possibilitaram verificar o efeito de doses de nitrogênio na produtividade de grãos de trigo (Millner et al., 1994; Frizzone et al., 1996; Zagonel et al., 2002; Trindade et al., 2006; Heinemann et al., 2006). Por outro lado, Silva (1991) não encontrou efeito significativo do nitrogênio na produtividade de grãos, em virtude da contribuição do nitrogênio residual da lavoura de soja cultivada anteriormente.

As médias do número de grãos por espiga, do número de grãos por espigueta, do número de grãos por $\mathrm{m}^{2} \mathrm{e}$ da massa de mil grãos em função da dose de $\mathrm{N}$, estão apresentadas na Tabela 6, com as respectivas equações de regressão ajustadas. Os dados elevados do coeficiente de determinação 0,98; 0,97; 0,88 e 0,89 indicam que grande parte da variação observada nas funções $y=f(N)$ pode ser "explicada" pela dose de nitrogênio.

Analisando-se as médias do número de grãos por espiga (Tabela 6) foi possível constatar maiores valores nas doses de $\mathrm{N}$ de 100, 200 e $400 \mathrm{~kg} \mathrm{ha}^{-1}$. Os menores valores do número de grãos por espiga ocorreram com as doses de $\mathrm{N}$ de 20 e 50 $\mathrm{kg} \mathrm{ha} \mathrm{a}^{-1}$. O incremento no número de grãos por espiga proporcionado pelo aumento das doses de nitrogênio também foi observado por Cazetta et al. (2007) e Frederick \& Camberato (1995). Por outro lado, Freitas et al. (1995) não observaram resposta do aumento das doses de $\mathrm{N}$ sobre o número de grãos por espiga.

Com relação ao número de grãos por espigueta (Tabela 6), verificou-se que a dose de $\mathrm{N}$ de 100,200 e $400 \mathrm{~kg} \mathrm{ha}^{-1}$ propiciou os maiores valores. Os menores valores ocorreram com as doses de $\mathrm{N}$ de 20 e $50 \mathrm{~kg} \mathrm{ha}^{-1}$. A ausência de resposta dessa variável às doses crescentes de $\mathrm{N}$ é frequentemente citada na literatura (Freitas et al., 1995; Teixeira Filho et al., 2007).

Tabela 6. M édias de número de grãos por espiga (N GE), número de grãos por espigueta (NGe), número de grãos por $\mathrm{m}^{2}$ (NG) e massa de mil grãos (M M G) em função da dose de nitrogênio (N) e respectivas equações de regressão $y=f(N)$ e coeficientes de determinação $R^{2}$

\begin{tabular}{|c|c|c|c|c|c|c|c|}
\hline \multirow{2}{*}{$\begin{array}{c}\text { Variável } \\
\text { dependente }\end{array}$} & \multicolumn{5}{|c|}{ Dose de N $\left(\mathrm{kg} \mathrm{ha}^{-1}\right)$} & \multirow{2}{*}{ Regressão $y=f(N)$} & \multirow{2}{*}{$\mathbf{R}^{2}$} \\
\hline & 20 & 50 & 100 & 200 & 400 & & \\
\hline NGE & $37,50 c^{*}$ & $39,90 \mathrm{bc}$ & $41,20 a b c$ & $43,50 a b$ & $44,40 \mathrm{a}$ & $y=-8 E-05 N^{2}+0,048 N+37,05$ & 0,978 \\
\hline NGe & $2,46 c$ & $2,58 b c$ & $2,64 a b$ & $2,74 a b$ & $2,79 a$ & $y=-3 E-06 N^{2}+0,002 N+2,444$ & 0,969 \\
\hline NG & $7846,00 \mathrm{~b}$ & $8656,00 a b$ & $9941,00 \mathrm{a}$ & $9983,00 \mathrm{a}$ & $10150,00 \mathrm{a}$ & $y=-0,036 N^{2}+20,53 N+7703$ & 0,877 \\
\hline MMG $(\mathrm{g})$ & $035,87 \mathrm{a}$ & $036,64 a$ & $37,84 a$ & 37,94 a & $37,14 a$ & $y=-5 E-05 N^{2}+0,022 N+35,63$ & 0,893 \\
\hline
\end{tabular}

* Na horizontal os valores seguidos pela mesma letra não diferem significativamente a 0,05 de probabilidade pelo teste de Tukey 
Avaliando-se o número de grãos por $\mathrm{m}^{2}$ (Tabela 6), observouse o maior valor com as doses de 100, 200 e $400 \mathrm{~kg} \mathrm{ha}^{-1} \mathrm{de} \mathrm{N}$. As doses de $\mathrm{N}$ de 20 e $50 \mathrm{~kg} \mathrm{ha}^{-1}$ propiciaram os menores valores. $\mathrm{O}$ incremento no número de grãos por $\mathrm{m}^{2}$ proporcionado pelo aumento da dose de N, também foi observado por Coelho et al. (1998).

As médias da massa de mil grãos (Tabela 6) não diferiram entre si em função dos tratamentos avaliados; todavia, houve resposta quadrática, conforme a equação de regressão ajustada. Os valores obtidos concordam com Zagonel et al. (2002) e indicam que a variação no rendimento de grãos, em função das diferentes doses de nitrogênio, não foi devida à variação do peso dos grãos; no entanto, as respostas da massa de mil grãos à adubação nitrogenada são muito variáveis na literatura. Frizzone et al. (1996), verificaram que o suprimento de nitrogênio pouco contribuiu para o aumento da massa de mil grãos. Por sua vez, Grundy et al. (1996), obtiveram aumento desse componente com a utilização de doses mais elevadas de nitrogênio.

Os dados do teor de proteína bruta em função da lâmina de água e nitrogênio e as respectivas equações de regressão em função de $\mathrm{N}$, apresentaram coeficientes de determinação superiores a $90 \%$ confirmando que no máximo $10 \%$ da variação observada não são explicados pelo nitrogênio; o que está em consonância com o fato de o nitrogênio ser um elemento básico na constituição da proteína.

Comparando-se as médias do teor de proteína bruta pelo teste de Tukey a 0,05 de probabilidade (Tabela 7), verificou-se, para todas as lâminas de água, que os maiores valores dessa variável ocorreram com a dose de $400 \mathrm{~kg} \mathrm{~N} \mathrm{ha}^{-1}$, comportamento este explicado pelo fato do nitrogênio ser elemento fundamental na constituição das proteínas.

Independentemente da lâmina de água, os teores de proteína bruta nas doses de $\mathrm{N}$ de 400 e $200 \mathrm{~kg} \mathrm{ha}^{-1}$ não diferiram estatisticamente entre si. Na lâmina de $120 \mathrm{~mm}$, o teor de proteína bruta obtido com a dose de $\mathrm{N}$ de $400 \mathrm{~kg}^{-1}$ não diferiu estatisticamente dos obtidos com as doses de 50, $100 \mathrm{e}$ $200 \mathrm{~kg} \mathrm{~N} \mathrm{ha}^{-1}$.

Para as doses de 200 e $400 \mathrm{~kg} \mathrm{~N} \mathrm{ha}^{-1}$, os maiores teores de proteína bruta ocorreram com a lâmina de $264 \mathrm{~mm}$; para a dose de $200 \mathrm{~kg} \mathrm{~N} \mathrm{ha}^{-1}$, o maior teor de proteína bruta não diferiu estatisticamente dos teores obtidos com as lâminas de 342 e 392 mm; nesta dose de nitrogênio, em todas as lâminas de água os teores de proteína bruta não diferiram daqueles obtidos com a dose de $400 \mathrm{~kg} \mathrm{~N} \mathrm{ha}^{-1}$.

Na Figura 2 estão as equações de regressão das variáveis dependentes, número de espiguetas por espiga, massa do hectolitro, número de queda e energia de deformação da massa,

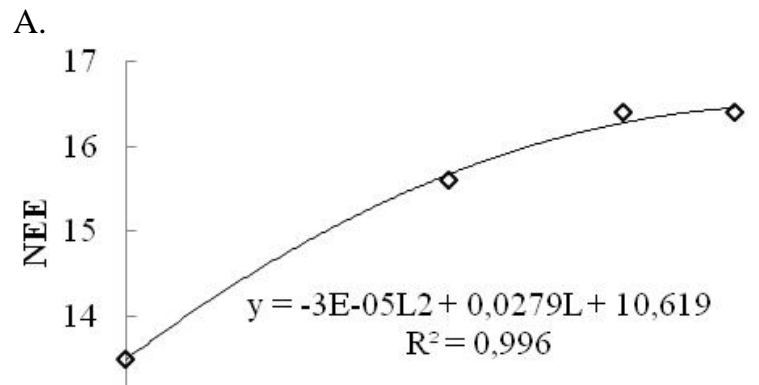

B.

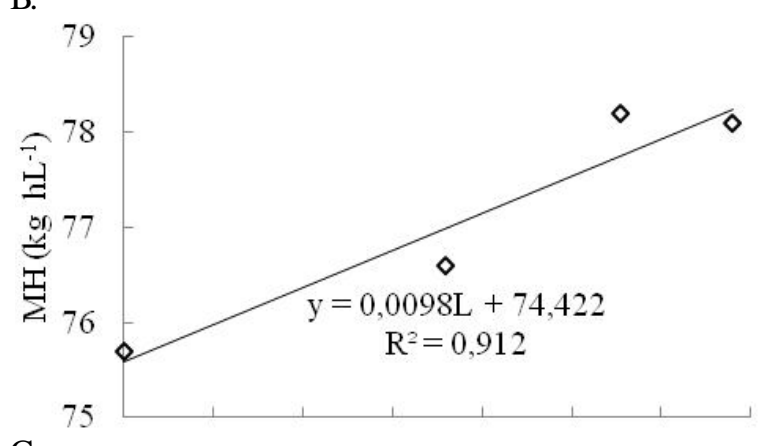

C.

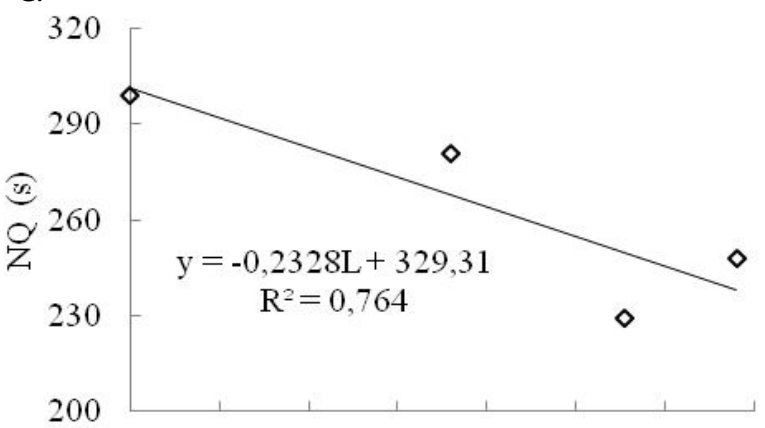

D.

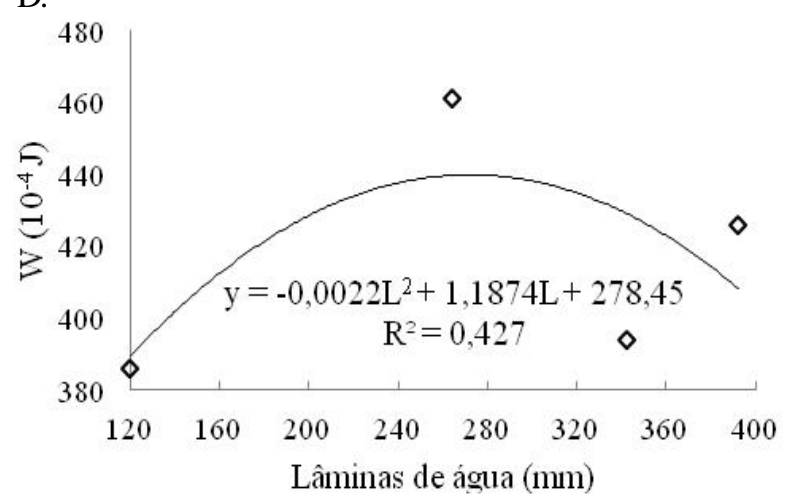

Figura 2. Equações de regressão do número de espiguetas por espiga (A), da massa do hectolitro (B), do número de queda (C) e da energia de deformação da massa (D) em função de lâminas de água

Tabela 7. M édias do teor de proteína bruta (\%) em função da lâmina de água, em mm, e da dose de nitrogênio ( $\mathrm{N}$ ), em $\mathrm{kg} \mathrm{ha}^{-1}$ com as respectivas equações de regressão, em que y é a variável resposta

\begin{tabular}{clllllll}
\hline Lâmina de & \multicolumn{9}{c}{ Dose de N (kg ha-1) } & & \multirow{2}{*}{ Regressão $\mathbf{y}=\mathbf{f}(\mathbf{N})$} \\
\cline { 2 - 6 } água $(\mathbf{m m})$ & $\mathbf{2 0}$ & $\mathbf{5 0}$ & $\mathbf{1 0 0}$ & $\mathbf{2 0 0}$ & $\mathbf{4 0 0}$ & & $\mathbf{R}^{2}$ \\
120 & $14,8 \mathrm{Ba} *$ & $15,4 \mathrm{Aba}$ & $16,1 \mathrm{Aba}$ & $16,2 \mathrm{ABb}$ & $16,6 \mathrm{Ab}$ & & $\mathrm{y}=-2 \mathrm{E}-05 \mathrm{~N}^{2}+0,012 \mathrm{~N}+14.76$ \\
264 & $13,4 \mathrm{Cb}$ & $14,0 \mathrm{Cb}$ & $16,0 \mathrm{Bab}$ & $17,6 \mathrm{Aa}$ & $19,0 \mathrm{Aa}$ & & $\mathrm{y}=-5 \mathrm{E}-05 \mathrm{~N}^{2}+0,035 \mathrm{~N}+12.64$ \\
342 & $13,1 \mathrm{Cb}$ & $13,6 \mathrm{BCb}$ & $14,8 \mathrm{Bb}$ & $16,3 \mathrm{Aab}$ & $16,5 \mathrm{Ab}$ & & $\mathrm{y}=-4 \mathrm{E}-05 \mathrm{~N}^{2}+0,027 \mathrm{~N}+12.45$ \\
392 & $14,1 \mathrm{Cab}$ & $14,8 \mathrm{Cab}$ & $15,5 \mathrm{BCab}$ & $16,8 \mathrm{ABab}$ & $17,0 \mathrm{Ab}$ & & $\mathrm{y}=-4 \mathrm{E}-05 \mathrm{~N}^{2}+0,022 \mathrm{~N}+13.68$ \\
\hline
\end{tabular}

* Médias seguidas da mesma letra maiúscula na horizontal e minúscula na vertical, não diferem significativamente a 0,05 de probabilidade pelo teste de Tukey. CV (\%) = 4,57 
em função das lâminas de água, única variável independente com efeito significativo sobre as variáveis dependentes supracitadas.

A função de resposta entre o número de espiguetas por espiga e as lâminas de água aplicadas, está apresentada na Figura 2A. Dentro do intervalo avaliado o ajuste obtido pela análise de regressão mostrou que a variável em questão apresentou resposta quadrática ao aumento da lâmina de água. A maior lâmina de água aplicada nesse experimento não correspondeu a uma lâmina acima da ideal ajustada (465 $\mathrm{mm})$.

A partir do ajuste obtido pela análise de regressão, constatase que houve comportamento linear crescente para a massa do hectolitro em função do aumento da lâmina de água (Figura 2B). Este comportamento pode ser explicado pelo fato de o fornecimento de água favorecer o enchimento de grãos aumentando, assim, sua massa. Scalco et al. (2002), também observaram tendência de aumento da massa do hectolitro com o aumento da lâmina de água.

A massa do hectolitro é um índice referente ao rendimento dos grãos em farinha ou sêmola; desta forma, espera-se que amostras com elevada massa do hectolitro apresentem maiores rendimentos. Nos tratamentos que receberam lâminas de água menores do que $365 \mathrm{~mm}$, os valores da massa do hectolitro se situaram abaixo de $78 \mathrm{~kg} \mathrm{hL}^{-1}$, valor mínimo exigido para a classificação do trigo como tipo 1 (Brasil, 2001). A venda da produção com valor inferior ao dessa massa, sofre desvalorização.

Pela análise de regressão ficou evidenciado decréscimo nos valores do número de queda com o aumento das lâminas de água (Figura 2C), sendo possível inferir que em menores lâminas de água ocorre menor atividade da enzima á-amilase. A farinha pode ser considerada ideal para a panificação quando o valor de número de queda se encontra no intervalo de tempo entre 250 a 350 segundos. Neste trabalho, valores dentro desse intervalo foram obtidos quando se aplicaram lâminas de água menores que $340 \mathrm{~mm}$.

O termo $L^{2}$ não apareceu na Eq. 1 devido à sua insignificância estatística no modelo de regressão proposto, permitindo-se inferir, por meio da análise matemática dessa equação, que produtividades maiores poderiam ser alcançadas com a aplicação de lâminas de água maiores que 392 mm; entretanto, aplicações de lâminas de água maiores afetariam negativamente o número de queda, comportamento que indica a necessidade do estabelecimento de lâminas que atendam tanto ao critério de produtividade quanto ao de qualidade.

Observaram-se elevados coeficientes de determinação para todas as variáveis apresentadas na Figura 2, exceto para a energia de deformação da massa (Figura 2D); isto demonstrou a discreta resposta dessa variável à variável independente lâmina de água, resultado que discorda do encontrado por Scalco et al. (2002), os quais, estudando quatro lâminas de irrigação e quatro doses de nitrogênio, constataram que os valores da energia de deformação da massa reduziram à medida em que se aumentou a lâmina de irrigação nos tratamentos que receberam 120 e $180 \mathrm{~kg} \mathrm{ha}^{-1}$ de sulfato de amônio.

\section{CONCLUSÕES}

1. Variações na produtividade de grãos ocorreram em função das doses de nitrogênio com diferentes pontos de ótimo, conforme as lâminas de água aplicada.

2. O modelo de regressão proposto para a produtividade estima satisfatoriamente esta variável levando em conta a interação dupla, evidenciando maior efeito da lâmina de água em relação à dose de nitrogênio.

3. Os fatores lâmina de água e dose de nitrogênio, contribuíram para o teor de proteína bruta, sendo esta influenciada significativamente pela dose de nitrogênio, dentro de cada lâmina de água.

4. O comportamento da massa do hectolitro e do número de queda com relação à lâmina de água aplicada, indica a necessidade de um controle rígido da irrigação para esta cultivar de trigo.

\section{LITERATURA CITADA}

AACC - American Association of Cereal Chemists. Approved methods. 10 ed. Saint Paul: AACC, 2000.

Brasil. Ministério da Agricultura e Reforma Agrária. Secretaria Nacional de Defesa Agropecuária. Regras de análises para sementes. Brasília: Editora do Ministério da Agricultura e Reforma Agrária, 1992. 1p.

Brasil. Ministério da Agricultura, Pecuária e Abastecimento. Instrução Normativa $\mathrm{n}^{\circ} 7$, de 15 de agosto de 2001. Lex: Diário Oficial da União, Brasília, seção 1, p.33, ago, 2001.

Cazetta, D. A.; Fornasieri, D.; Arf, O. Resposta de cultivares de trigo e triticale ao nitrogênio no sistema de plantio direto. Científica, v.35, p.155-165, 2007.

CONAB - Companhia Brasileira de Abastecimento. Acompanhamento da safra brasileira: Grãos: Safra 2008/2009, décimo levantamento, Julho 2009/Companhia Nacional de Abastecimento. Brasília: CONAB, 2009. <http:// www.conab.gov.br>. 15 Jul. 2009.

Coelho, M. A. O.; Souza, M. A.; Sediyama, T.; Ribeiro, A. C.; Sediyama, C. S. Resposta da produtividade de grãos e outras características agronômicas do trigo Embrapa-22 irrigado ao nitrogênio em cobertura. Revista Brasileira de Ciência do Solo, v.22, p.555-561, 1998.

EMBRAPA - Empresa Brasileira de Pesquisa Agropecuária. Avaliação de cultivares de trigo em sistema de manejo tradicional e otimizado, Passo Fundo: EMBRAPA/CNPT, 2004. 5p. Documentos, 58

EMBRAPA- Empresa Brasileira de Pesquisa Agropecuária. BRS 254 - Trigo melhorador: cultivar com alta qualidade industrial para a região do Cerrado. Brasília: Embrapa Cerrados, 2008. 18p. Documentos, 228

Frederick, J. R.; Camberato, J. J. Water and nitrogen effects on winter in the Southeastern Coastal Plain: I. Grain yield and kernel traits. Agronomy Journal, v.87, p.521-526, 1995.

Freitas, J. C.; Camargo, C. E. O.; Ferreira Filho, A. W. P.; Castro, J. L. Eficiência e resposta de genótipos de trigo ao nitrogênio. Revista Brasileira de Ciência do Solo, v.19, p.229234, 1995. 
Frizzone, J. A.; Mello Júnior, A. V.; Folegatti, M. V.; Botrel, T. A. Efeito de diferentes níveis de irrigação e adubação nitrogenada sobre componentes de produtividade da cultura do trigo. Pesquisa Agropecuária Brasileira, v.31, p.425-434, 1996.

Grundy, A. C.; Boatman, N. D.; Fround Williams, R. J. Effects of herbicide and nitrogen fertilizer application on grain yield and quality of wheat and barley. Journal of Agriculture Science, v.126, p.379-385, 1996.

Guarienti, M. E.; Ciacco, C. F.; Cunha, G. R. da; Duca, L. J. A. del; Camargo, C. M. O. Avaliação do efeito de variáveis meteorológicas na qualidade industrial e no rendimento de grãos de trigo pelo emprego de análise de componentes principais. Ciência e Tecnologia de Alimentos, v.23, p.500510,2003.

Hanks, R. J.; Keller, J.; Rasmussem, V. P.; Wilson, G. A. Line source sprinkler for continuous variable irrigation-crop production studies. Soil Science Society of America Journal, v.40, p.426-429, 1976.

Heinemann, A. B.; Stone, L. F.; Didonet, A. D.; Trindade M. G.; Soares. B. B.; Moreira J. A. A.; Cánovas A. D. Eficiência de uso da radiação solar na produtividade do trigo decorrente da adubação nitrogenada. Revista Brasileira de Engenharia Agrícola e Ambiental, v.10, p.352-356, 2006.

Millner, J. P.; Mcevan, J. M.; Valentine, I. Effect of late nitrogen on the yield and quality of spring sown 'Rongotea' wheat. Journal of Crop and Horticulture Science, v.22, p.187-194, 1994.
Mistro, J. C.; Camargo, C. E. O. Avaliação da produção de grãos e características agronômicas em genótipos de trigo, em 1999 e 2000. Bragantia, v.61, p.35-42, 2002.

Oliveira Júnior, M. P. de ; Silva, C. L. da ; Oliveira, C. A. da S. Rendimento físico e econômico da aveia preta no Distrito Federal. Revista Brasileira de Saúde e Produção Animal, v.11, p.14-1-24, 2010.

Scalco, M. S.; Faria, M. A. de; Germani, R.; Morais, A. R. de. Produtividade e qualidade industrial do trigo sob diferentes níveis de irrigação e adubação. Ciência Agrotécnica, v.26, p.400-410, 2002.

Schroeder, L. F. Farinhas mistas. Trigo e soja, .1, p.4-6, 1987.

Silva, D. B. Efeito do nitrogênio em cobertura sobre o trigo em sucessão a soja na região dos cerrados. Pesquisa Agropecuária Brasileira, v.26, p.1387-1392, 1991.

Teixeira Filho, M. C. M.; Buzetti, S.; Alvarez, R. C. F.; Freitas, J. G.; Arf, O.; Sá, M. E. Resposta de cultivares de trigo irrigado por aspersão ao nitrogênio em cobertura na região do Cerrado. Acta Scientiarum-Agronomy, v.29, p.421-425, 2007.

Trintade, M. G.; Stone, L. F.; Heinemann, A. B.; Abelardo, D. C.; Moreira, J. A. A. Nitrogênio e água como fatores de produtividade do trigo no Cerrado. Revista Brasileira de Engenharia Agrícola eAmbiental, v.10, p.24-29, 2006.

Zagonel, J.; Venâncio, W. S.; Kunz, R. P.; Tanamati, H. Doses de nitrogênio e densidades de plantas com e sem regulador de crescimento afetando o trigo, cultivar OR-1. Ciência Rural, v.32, p.25-29, 2002. 